This article was downloaded by: [University of Rochester]

On: 30 May 2013, At: 07:52

Publisher: Routledge

Informa Ltd Registered in England and Wales Registered Number: 1072954 Registered office: Mortimer House, 37-41 Mortimer Street, London W1T 3J H, UK

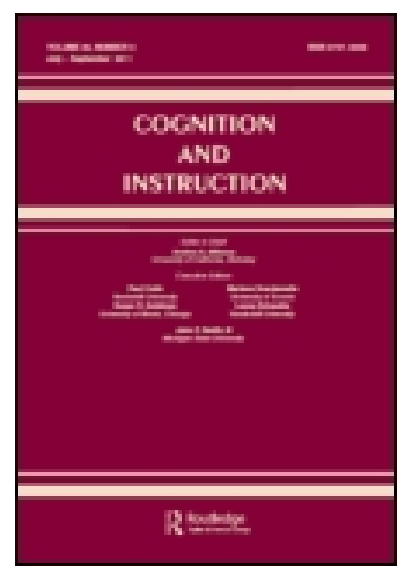

\title{
Cognition and Instruction
}

Publication details, including instructions for authors and subscription information:

http:// www. tandfonline.com/ loi/ hcgi20

\section{The Power of Mediating Artifacts in Group-Level Development of Mathematical Discourses}

\author{
Nancy Ares ${ }^{a}$, Walter M. Stroup ${ }^{b} \&$ Alfred R. Schademan ${ }^{a}$ \\ a University of Rochester, \\ ${ }^{\mathrm{b}}$ University of Texas at Austin, \\ Published online: 31 Dec 2008.
}

To cite this article: Nancy Ares, Walter M. Stroup \& Alfred R. Schademan (2009): The Power of Mediating Artifacts in Group-Level Development of Mathematical Discourses, Cognition and Instruction, 27:1, 1-24

To link to this article: http:// dx. doi.org/ 10.1080/ 07370000802584497

\section{PLEASE SCROLL DOWN FOR ARTICLE}

Full terms and conditions of use: http://www.tandfonline.com/page/terms-and-conditions

This article may be used for research, teaching, and private study purposes. Any substantial or systematic reproduction, redistribution, reselling, loan, sub-licensing, systematic supply, or distribution in any form to anyone is expressly forbidden.

The publisher does not give any warranty express or implied or make any representation that the contents will be complete or accurate or up to date. The accuracy of any instructions, formulae, and drug doses should be independently verified with primary sources. The publisher shall not be liable for any loss, actions, claims, proceedings, demand, or costs or damages whatsoever or howsoever caused arising directly or indirectly in connection with or arising out of the use of this material. 


\title{
The Power of Mediating Artifacts in Group-Level Development of Mathematical Discourses
}

\author{
Nancy Ares \\ University of Rochester \\ Walter M. Stroup \\ University of Texas at Austin \\ Alfred R. Schademan \\ University of Rochester
}

\begin{abstract}
A new generation of networked classroom technology immerses students and teachers in the grouplevel construction of powerful mathematical and scientific concepts. We examine these networks from a sociocultural point of view as a new form of mediating artifact. We present a mixed-method, microgenetic analysis to characterize students' appropriation of mathematical content and practice as mediated by the Participatory Simulations system. Central findings of the study are that networked activities provided the opportunity for students and the teacher to: (a) act on multiple representations, (b) create collectively a linked set of mathematical objects that they could examine and discuss together, and (c) exercise agency in the production of mathematical discourse and practice. These opportunities fostered the development of powerful mathematical discourse.
\end{abstract}

A new generation of networked classroom technology immerses students and teachers in the group-level construction of powerful mathematical and scientific concepts, providing an important opportunity to build understanding of the social construction of mathematical knowledge and practice (for example, HubNet and Participatory Simulations, Wilensky \& Stroup, 2000; SimCalc: Kaput \& Hegedus, 2002). We present a case study that examines the role of mediating artifacts involved in a classroom using this new technology. Our analyses of the particular role of networked systems - specifically, those that require collective engagement for mathematical objects to emerge for groups' analysis and discussion-provide insight into the ways that such tools may leverage the power of groups and foster generative mathematical discourse.

Our research question was, "In what ways do networked teaching and learning technologies, by shaping the way you learn, shape what you learn?" We present a mixed-method, microgenetic analysis of a classroom session in which the Elevators Participatory Simulation (PartSim)

Correspondence should be addressed to Nancy Ares, Warner Graduate School, University of Rochester, P.O. Box 270425, Rochester, NY 14627. E-mail: nancy.ares@ rochester.edu 
(Wilensky \& Stroup, 1999; described later) was implemented. The Hubnet and PartSim system includes a wireless network of graphing calculators that collects students' individual input to their calculators, and projects a real-time display of the emergent ${ }^{1}$ system formed from their collective inputs on a screen at the front of the room. These simulations are participatory because students take on roles of individual agents (e.g., controlling a traffic light in a transportation system) and then observe how the behavior of the system as a whole emerges from their individual behaviors (e.g., traffic flow in the system). The results become the focus of in-class discussion and analysis. In the case of the Elevators PartSim that is the focus of this study, what emerges for the class to view and analyze are side-by-side displays of individual elevators, a collection of real-time emerging position versus time graphs, and a collection of real-time emerging velocity graphs.

A broad goal of the associated curriculum is engaging all students in the analysis of complexity and dynamic systems (Wilensky \& Stroup, 2000) and in this study, exploring the mathematics of change and variation through "... graphical renderings of rate- the velocity of the elevator-and amount-which floor the elevator is on" (Stroup, Ares, \& Hurford, 2004, p. 48). The mathematics of change and variation is critical to students' learning, given its place in mathematics, the sciences, and the social sciences, as well as its importance as a feature of everyday experience (Dede, 2000; Kaput, 1994; Noble, Nemirovsky, Wright, \& Tierney, 2001; Roschelle, Kaput, \& Stroup, 2000).

Although networked technologies are designed to leverage the power of group interactions, little work has examined their roles in the development of important classroom-level mathematical content and practice. Our work explores empirically, from a sociocultural point of view, the mediating role of networked technologies in the development of group-level construction of mathematical discourse. To track the evolving discourse, we combined detailed coding of classroom talk before, during, and after the use of the network with analyses of participant roles and interactions. Our goal in taking this approach is "... to understand how [PartSims activity is] qualified by local conditions, and thus develop more sophisticated descriptions and more powerful explanations" (Miles \& Huberman, 1994, p. 172). We begin with a detailed description of the Elevators PartSim to give a picture of networked classroom activity and interactions.

\section{THE ELEVATORS PARTICIPATORY SIMULATION}

In this Participatory Simulation, students use the software on their calculators to control the motion of an elevator by deciding how many floors it will move up or down in one second intervals (see Figure 1). For example, the arrangement in Figure 1 would have the elevator move up one floor each between seconds 0 and 1, and 1 and 2, then up three floors between seconds 2 and 3, and then up one more floor between seconds 3 and 4, ending on the 6th floor. Students first run the simulation on their calculators to explore how the motion of the elevator (i.e., its speed and location over time) is related to different possible arrangements. Students build understanding by varying the arrangements to see how differently shaped arrangements result in different motions of a simulated elevator and different position-time graphs. For example, students examining the arrangement in Figure 1 and the attendant elevator motion may notice that

\footnotetext{
${ }^{1}$ Emergence is a quality of both the mathematical objects that develop via the networked system itself and the mathematical content, discourse, and practice that develop from the activity and interactions of participants, mediated by the artifacts involved.
} 

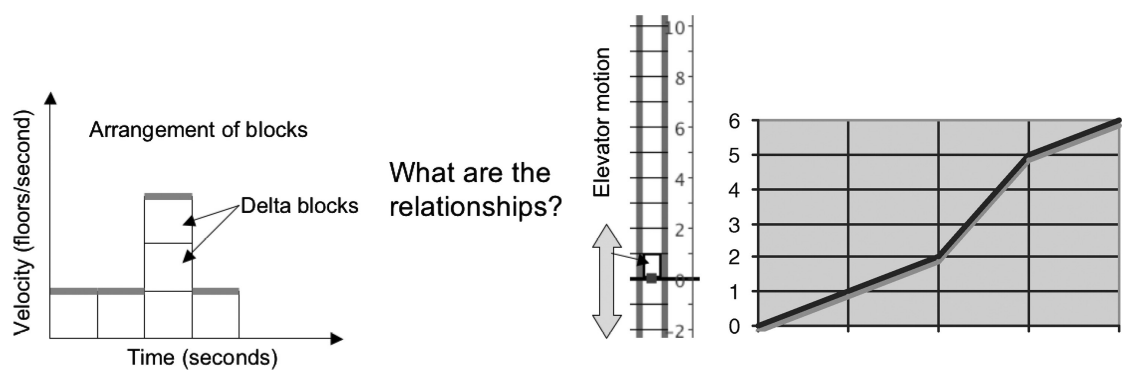

FIGURE 1 Required arrangement and related position graph.

the elevator moves slowly to the first floor, then slowly to the second floor, then quickly to the fifth floor, then slowly to end on the sixth floor. In examining the resulting position-time graph, they may notice that the varying slope of the line corresponds to the changing speed of the elevator and the arrangement of blocks in the velocity time graph. They then send their arrangements to the network, and the system projects each elevator's motion and emerging real-time graphs of the elevators' velocity and position in an upfront display (see Figure 2). If more than one student

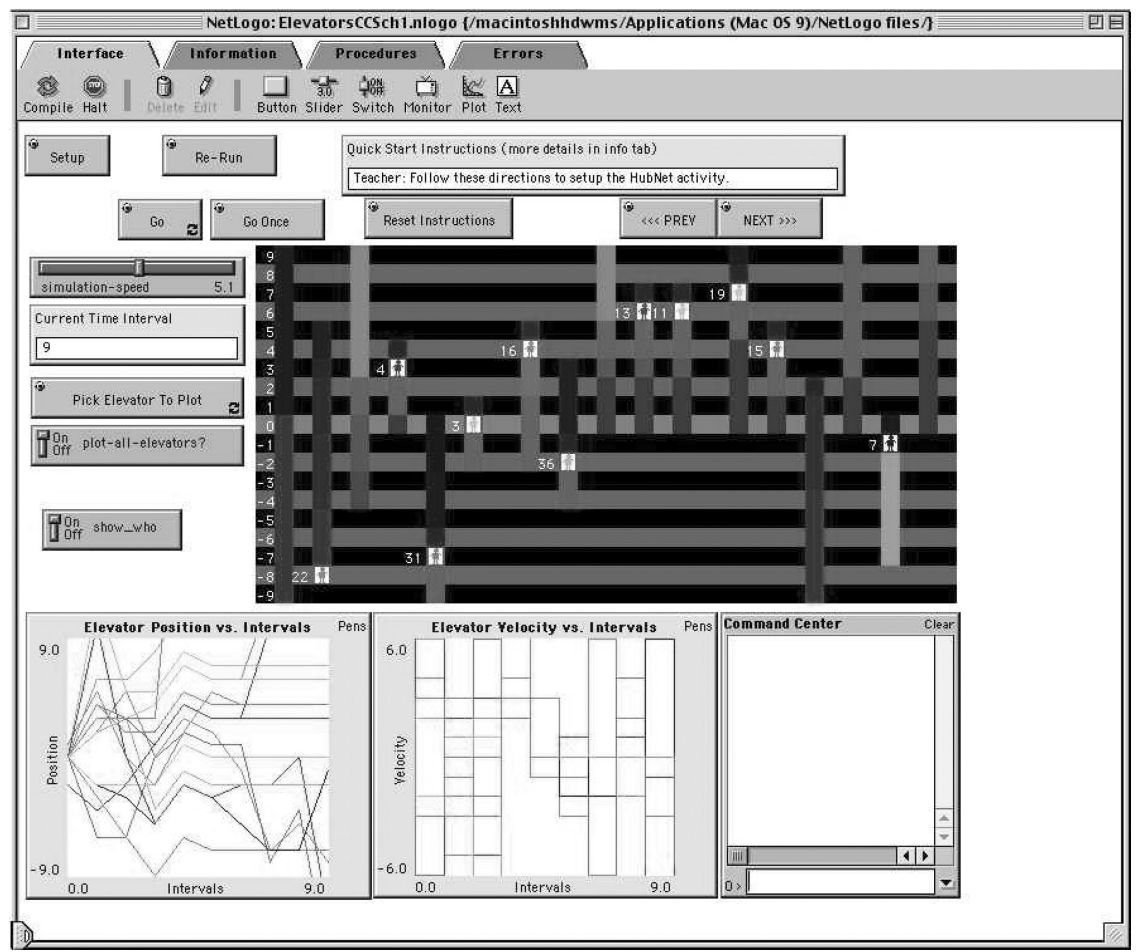

FIGURE 2 Arrangements of blocks of area control the motion of a simulated elevator. 
sends the same arrangement, the class may notice or the teacher may point out and discuss that the elevators move together (the teacher and students in this case study spoke about a "dance"), that they end on the same floor, and that the position-time graphs are all the same line. Using this approach, students use examples they create to explore rate in a qualitative or comparative way. The approach is qualitative because rather than starting with ratio-based concepts and forms of measurement (e.g., floors per second), the students start off by talking in terms of relative speeds and in terms of "going" some number of floors "in" a given time interval. Given the role of the networked system in fostering these interactions, we turned to sociocultural theory to examine them as mediating tools.

\title{
THEORETICAL FRAMEWORK: MEDIATING ROLES OF TECHNOLOGIES AND ARTIFACTS
}

Human activity and learning are profoundly influenced, or mediated, by the use of psychological and physical tools (e.g., language, computers) (cf., Vygotsky, 1987; Cole \& Engeström, 1993; Wertsch, 1995). Mediating artifacts are defined as externally oriented technical tools (e.g., hammers, texts) and internally oriented psychological tools or signs (e.g., language, number systems). Vygotsky (1987) held that learning occurs first on the inter-mental plane as individuals interact with others and with mediating artifacts in practical, culturally defined activity. Individuals then appropriate that socially mediated learning on the intra-mental plane. As Smagorinsky (1995, 925) notes:

\begin{abstract}
From this perspective, the mind is unlimited in the sense that its development is inseparable from the tools of mediation. ... The means of mediation can also be invisible yet powerfully influential in shaping thought and communication, such as the speech genres that govern discourse in specific sociocultural settings, or so embedded in our daily lives that we do not notice them as tools, such as a pencil or appointment book. These tools have no inherent value and use, but take on meaning as tools with specific values and uses through the historical cultural functions that members of a society have found for and attributed to them.
\end{abstract}

Further, Cole (1996) argues that artifacts serve a dual function as both conceptual and physical tools, providing resources for thinking and for acting. In one sense these networks are an externally oriented tool-like hammers or written text-in that they are physical things that provide a tool or medium of exchange. In another sense they are internally oriented signs-like languages or number systems - in that they support the expression of relations and symbolizations among participants. Through artifacts' dual function, the agency of the individual and the nature of the object are changed through mediated activity.

We seek to heighten attention to group-level discourse and developing understandings that are mediated by this new generation of highly interactive networks. We pay particular attention to the roles of students and their teacher, the mediating function of important artifacts (e.g., the networked technology, calculators, white board), and to the emergent object of the activity. Because we are examining the development of mathematical discourse, we include in our framework Gee's (1999) sociocultural view that discourse is "ways of acting, interacting, feeling, believing, valuing, together with other people and with various sorts of characteristic objects, symbols, tools, 
and technologies" (p. 7). Theory and method guided by this perspective highlight that mathematics is communication (National Council of Teachers of Mathematics, 2006), and discourse and practices (Moschkovich, 2002; Gee, 1999), through which groups, “... mathematize situations, communicate about these situations, and use resources for mathematizing and communicating" (Moschkovich, 2002, p. 197). These perspectives on mediated activity and developing discourse direct our attention to the ways that mathematical reasoning is manifested in discourse. Further, they guide examination of mediated action, participants' roles, and mathematical discourse as mutually constituting features of classroom activity.

\section{RELATED LITERATURE}

Sociocultural researchers examining classroom learning have recently demonstrated the mediating functions of a variety of artifacts, including dialogue (Wells, 2002; Damazio, 2001), reflective discourse (Hershkowitz \& Schwarz, 1999), and metaphorical and conjectured ideas (Hung, 2001, 2002). In examining technologies as artifacts, Roschelle and Pea (1999) cite three features of innovative technologies aimed at fostering generative, meaningful learning: "shared active representations, ... advanced socio-cognitive scaffolding, ... [and] tools which foster self-improving communities" (pp. 6, 7). Such systems are the focus of this research and the related literature examined here.

As innovative technologies make their way into classrooms, researchers are attempting to understand the complex roles they play in group-level processes. McClain and Cobb (2001) found that computer-generated graphical representations: (a) encouraged students to act on data through enabling creation and manipulation of data sets and (b) supported teacher ability to create imagery of a situation, allowing students to relate graphs to their real world understandings. Saxe's (2002) examination of artifacts' form and function found that different computer artifacts served varying functions. In one case with multiple data sets, students' examination involved proportional reasoning, which was different than when they examined data on a case-by-case basis. Further, he found that the specific nature of computer-based artifacts had implications for the formation of student arguments and activity goals. Taking a more cognitive approach to analyzing the role of computer-based representations of data in math classrooms, Cobb (2002) found that "symbolizing was an integral aspect of mathematical reasoning" (p. 187). Symbols and representations entered into a reciprocal relationship with both cognitive structures and understandings of the existing goals of an activity. From this dialectical perspective, symbols and their meanings were "mutually constitutive and co-emerge[d]" (p. 188) as they were used in situated activity. These studies highlight that artifacts, as externally oriented signs (e.g., data sets used for comparison rather than a data set for examination), mediate the interactions of participants and emergent outcomes by shaping the types of reasoning involved as internally oriented tools (e.g., arithmetic versus proportional reasoning).

Schwarz and Hershkowitz (2001) argue, following Kaput (1992), that computer tools afford users the ability to act on multiple representations of phenomena. They examined mediating roles of computer "algebraic, graphical, and tabular representations" (p. 266) in the shared construction of the meaning of mathematical functions. Students' flexible use of graphing calculators' multiple representations and the fact that those representations were inherently ambiguous (each was a partial representation of the phenomenon) produced contexts in which group-level understanding 
was co-constructed. The various representations were the focus of both internal reflection and external action that fostered shared meaning, mediating groups' sense making and development of mathematical discourse and practice.

Our work extends these findings because the networked activities studied are markedly different from those used in the aforementioned studies. A central feature of HubNet and Participatory Simulations is that they require groups' collective engagement for the activity to proceed. Further, these activities are designed to be generative in that, "Learners create a space-or coordinated collection-of expressive artifacts and actions in relation to some shared task or set of rules. The structures that are created ... are not determined in advance but are co-constructed by learners as their sense-making evolves and develops" (Stroup, Ares, \& Hurford, 2004, p. 1403). Structures can be such things as a collection of expressions that are the same in some mathematical way (e.g., how many ways can we make $4 x$ ?) or strategies to attain some shared goal (optimize traffic flow collectively based on graphs of average speed, average wait time). In short, PartSims are designed to leverage group-level interactions, with groups' co-construction of mathematical dialogue and reasoning emerging as the group acts on the multiple representations and notational systems involved. Our analyses of the particular role of networked systems provide insight into the features of these artifacts that leverage the power of groups and foster constructive mathematical discourse.

\section{METHOD}

\section{The Setting}

The school was a public charter school in a mid-size city in the western United States, committed to democratic governance, problem-based learning, and integrated curricula. Approximately 50\% of the students in the school were Hispanic, 21\% African American, 25\% European American, and $4 \%$ Pacific Islander, Native American, and recent immigrants from a variety of countries; those demographics were reflected in the class that was the focus of this study. The class involved 14 students ( 5 girls and 9 boys) who were in their first or second year of high school.

The school designated the class as a first-year Integrated Mathematics Project (IMP) (Fendel, Reseck, Alper, \& Fraser, 1997) class, following the scope and sequence provided by this curriculum that focuses on "problem-solving and communication skills ... a shift in instruction away from routine manipulation of symbols and procedures toward an in-depth conceptual understanding of mathematics" (http://www.mathimp.org/general_info/iis/section2_1.html). The teacher, Ms. Gardner, ${ }^{2}$ a European-American teacher with 15 years of experience, was interested in using networked classroom technology as complementary to the IMP curriculum. Support for her use of PartSims included attending a weeklong summer workshop and ongoing collaboration with researchers during the academic year before, during, and after each of the three, networked activities she implemented in her classrooms. During the implementation, the researchers provided technical support (helping students log into the program, trouble-shooting) and occasionally interjected comments (e.g., reacting verbally or directing attention to elevator motions in the upfront space).

\footnotetext{
${ }^{2}$ All names are pseudonyms. "Student" is used if students could not be identified by name from the video.
} 


\section{Data and Analyses}

We report on one 90-minute classroom session taught by Gardner that was videotaped with the network in use. We limited ourselves to one session to focus on "thick" descriptions (Geertz, 1973) and conduct in-depth analyses of classroom activity. Our focus was on whole-class activity, given that co-construction of mathematical objects and understanding, as well as emergence of content and understanding, is a central feature of network-mediated classroom interactions.

Analyzing Classroom Talk. Whole-class discourse was coded as to the type of comment or question (e.g., observation, explanation), drawing on the work of Brenner and Moschkovich (2002) on everyday and academic mathematics (see Appendix), but including codes we found to be important in the class' activity. The first author developed an initial set of codes drawing directly from literature on everyday and academic mathematics. Emergent codes were added using a grounded approach (Strauss \& Corbin, 1990) as she coded video data using the literature-derived scheme. The third author used the elaborated scheme with an eye to evaluating its usefulness and to adding or deleting codes. We arrived at the final scheme through a process of discussion, independent coding, and more discussion until reaching consensus. This final scheme was then used to complete the analysis of the classroom session reported on here.

Frequency diagrams were constructed to examine change in the numbers of comments or questions within coding categories over the course of each class session. We examined the developing whole-class discourse for proportion of teacher versus student verbal contribution to examine the balance between teacher and student talk, as well as the variation in that balance across the class session. We then examined contributions across episodes to characterize the nature of students' and Gardner's verbal contributions (e.g., everyday, academic mathematics).

Analyzing Roles, Mediating Artifacts, Discourse, and Practice. The videotape was transcribed as field notes so we could analyze patterns of participation and reasoning and to deepen our analysis beyond frequency data. Episodes, or naturally occurring shifts in activity (e.g., when the focus of the class changed or when they moved from independent to whole class activity), were identified, also using a grounded approach, so that we could describe the pattern of learning activities over the course of the whole class period; episode names reflect themes that describe those activities. For example, the terms visualize, predict, and explain refer to when students and Gardner engaged in forming mental images of relationships among representations and anticipating and/or explaining what they would see in the upfront display. Interpretation involved the class' talking about the relationships among representations, that is, the meaning of parallel or intersecting position graphs.

The following questions framed our analysis within and across episodes: What features of the Elevators lesson support the group-level development of mathematical discourse and reasoning? What artifacts were mediating the activity? How did the Elevators PartSim promote a particular course of development? We analyzed the transcript for roles that Gardner and the students played in the activity (e.g., Gardner's choices of verbal and electronic contributions to highlight, students' individual verbal and electronic contributions that indicated important insights or questions), and the roles that mediating artifacts played in the emerging discourse. This analysis was based on 
Moshkovich's (2002) notion of mathematics as discursive practice. She draws on Gee (1999) to examine mathematical practice as "talking and acting in ways that mathematically competent people talk and act. .... [including] particular modes of argument, such as precision, brevity, and logical coherence, ... [and, for example] abstracting, generalizing and searching for certainty" (p. 190), as well as uses of artifacts such as mathematical representations. Thus, our analysis focused on examining the class' discursive practices in terms of mathematical reasoning (e.g., generalizing; predicting, exploring, and/or explaining relationships), disciplinary content (e.g., understanding slope, rate, parallel lines), and engagement with artifacts (e.g., graphs, calculators, upfront space).

\section{RESULTS}

We present our findings in two parts. In the first part, we describe the way the class interacted with the Elevators Participatory Simulation, the sequence of episodes that unfolded, and the roles, artifacts, and discourse that emerged. The second section focuses more particularly on the mediating artifacts involved.

\section{Individuals, Artifacts and Outcomes}

In this section, we present results that illustrate the nature of the relationships among individuals (students and Gardner), mediating artifacts (e.g., real-time display, calculators, whiteboard), and objects (mathematical discourses and practices). We examine particular episodes chosen because they are representative of the discourse and interactions that took place during whole-class activity. Importantly, we do not claim that artifacts' use caused the varying discourses and outcomes, but attempt to highlight the individual-artifact-object relationships characterizing the activity.

Elevators. Before working with the networked technology, students were given a set of worksheets that had as a first challenge to create arrangements of blocks that included the one shown in Figure 3, but they could construct any arrangement on either side of the given blocks. ${ }^{3}$ Among the goals of this particular challenge was analysis of what the shared arrangements would produce in the graphs projected in the upfront space. The purpose of the worksheets was to scaffold students' understanding of the function of the arrangements of floors prior to moving to the electronic medium. Gardner explained that each block in an arrangement referred to a floor in a building, so their arrangements would control how many floors an elevator would move in one second (i.e., its velocity), as well as whether it moved up or down (i.e., position). They were also

\footnotetext{
${ }^{3}$ This approach is the delta-blocks approach to learning the math of change (Stroup, 1996, 2002) that was originally developed in late elementary, middle and high school classrooms as part of work on the SimCalc Project (SimCalc: Kaput \& Hegedus, 2002; http://www.simcalc.umassed.edu). The following is a summarized version of the Elevators Participatory Simulation used with learners in grades three through 12 that makes use of a simulation environment called MathWorlds (Kaput \& Roschelle, 1996, 2003).
} 

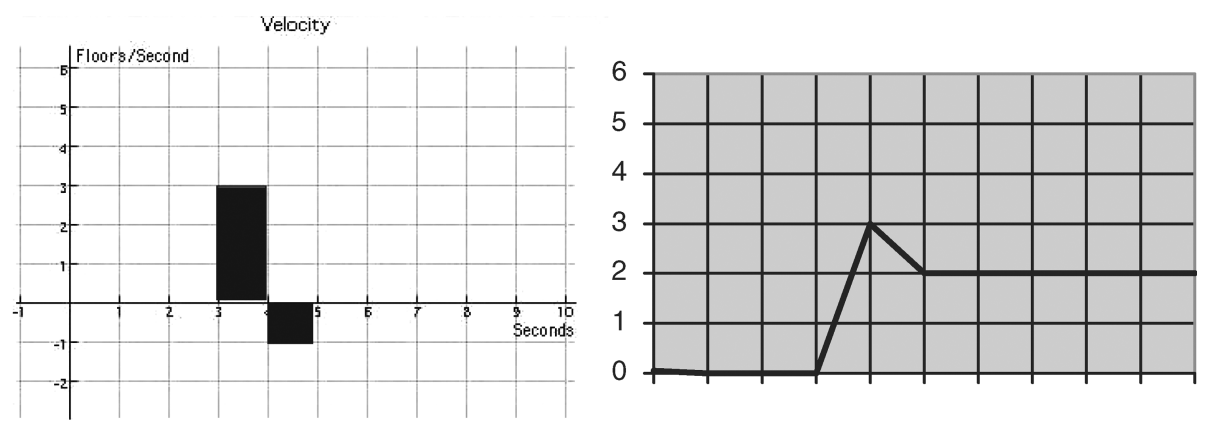

FIGURE 3 Projected screen (left) and enlarged view of the position vs. time graph (right).

asked to draw related position graphs that represented the motion of the elevator as controlled by their arrangements (Figure 3).

Once they drew their arrangements on the worksheets, students transferred them into their calculators by "dragging" the given horizontal velocity segments up or down until the arrangement in the calculator matched the shaded-in arrangement on their graph paper. Students ran the simulation to explore on the calculator screen how the motion of the elevator was related to different arrangements of blocks. When students' arrangements were sent to the network, the screen that was projected in front of the entire class showed all the elevators moving simultaneously and the related position and velocity graphs unfolding in real time below the simulated elevators (Figure 4). Notice that in the enlarged position versus time graph, most of the elevators move "fast" in a parallel fashion upward in the interval between seconds three and four (corresponding to the 3 blocks in Figure 3) and then down slowly (one block below the axis in Figure 3).

The Sequence of Episodes. The class engaged in three challenges. The first asked students to make a "complicated graph" that included use of 6 blocks in a predetermined arrangement
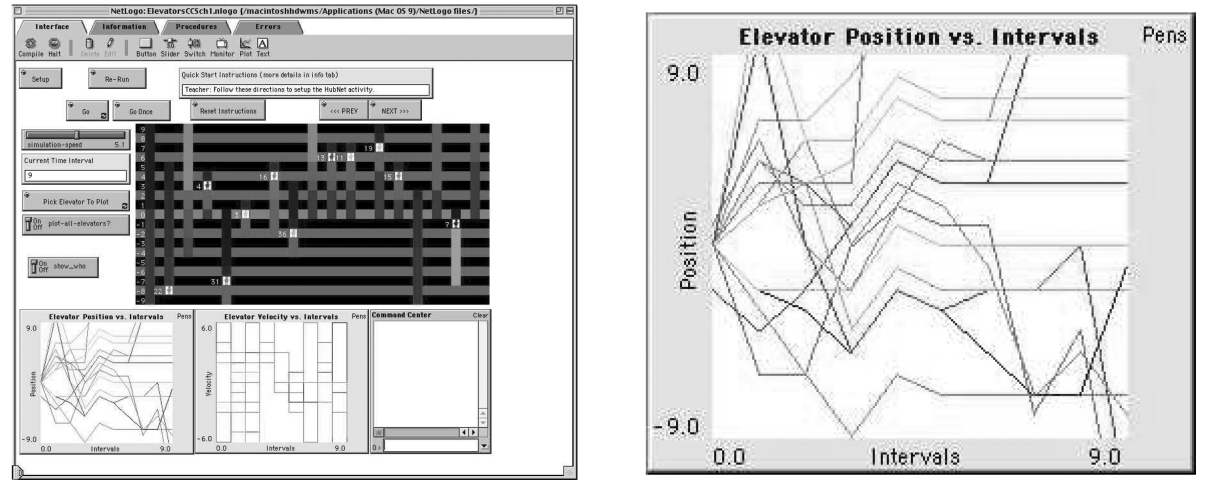

FIGURE 4 Student and teacher verbal contributions. 
(resulting in a display of a series of parallel position graphs when the arrangements were sent through the network). The second had them find a way of having the elevator end on the -2 floor, using as many blocks as they wanted. For both of these challenges, they were directed to draw the corresponding position graph on their worksheets and then send the arrangement through the network. The third had them create a velocity graph that included predetermined segments shown on a position graph, but that had blocks on either side of it as well. They were asked to draw both velocity and position graphs on their worksheets and then send the arrangement through the network. The sequence of episodes that emerged in our analysis presented next highlighted students' developing ideas about amount, rate, and the parallel and intersecting line segments that appeared in the real-time display. As seen in Table 1, three episodes focused on visualizing what would emerge when the collective contributions would be displayed up front, each followed by episodes that involved the class in describing and interpreting the objects they created individually and together (e.g., individual elevator motion, emergent graphs of velocity, and position over time). During the final two episodes the class became increasingly precise in its analyses and moved to evaluate their success as a group in meeting the third challenge. As seen later in the second data excerpt, one student's particularly fast-moving elevator provided a context for significant mathematical learning and, indeed, humor. Gardner introduced the metaphor of "dance" to describe the portions of the simulation where all students' elevators were to move in the same manner, and both she and her students used this to talk about the relations between graphical representations and the movement of the elevators (Visualize/Predict, Describe/Interpret episodes). As shown next, across the episodes, students' and Gardner's acting on and interpreting multiple representations of mathematical phenomena characterized the group-level discursive practices that emerged.

TABLE 1

Sequence of Classroom Episodes and Their Descriptions

\begin{tabular}{|c|c|}
\hline Episode & Description \\
\hline Review & Review challenge from previous day. \\
\hline Visualize/Explain & $\begin{array}{l}\text { Students and teacher visualize and predict what they will } \\
\text { see in the projected space. }\end{array}$ \\
\hline Interpret Multiple Representations & $\begin{array}{l}\text { Students and teacher interpret multiple representations in } \\
\text { the projected space. }\end{array}$ \\
\hline New Challenge & Teacher presents students with a new challenge. \\
\hline Simplify Challenge & Teacher simplifies the challenge for students. \\
\hline Visualize/Predict & Same as above. \\
\hline Describe/Interpret & $\begin{array}{l}\text { Students and teacher describe and interpret representations } \\
\text { in the projected space. }\end{array}$ \\
\hline New Challenge & Same as above. \\
\hline Precise Visualize/Prediction & $\begin{array}{l}\text { Teacher and student discourse becomes increasingly precise } \\
\text { in their visualizations and predictions of the projected } \\
\text { space. }\end{array}$ \\
\hline Evaluate Collective Construction & $\begin{array}{l}\text { Teachers and students evaluate their success in meeting the } \\
\text { third challenge. }\end{array}$ \\
\hline
\end{tabular}




\section{Roles, Artifacts, and Discourse}

The excerpts that follow are representative of the discourse and roles that emerged, mediated by the real-time display, the worksheet, and the calculators. Our analysis of the mathematical practices highlights Gardner and students' roles in predicting relationships among representations (e.g., velocity and position graphs in relation to motion of elevators), visualizing representations based on those predictions (e.g., parallel or intersecting position graphs), and interpreting, or co-constructing understandings of relationships between rate and amount. The analysis of the interactions also highlights the ways that Gardner managed the discourse to focus attention on particular representations, important student contributions, and mathematical content.

Visualize and Predict. The first exchange is from the Visualize/Predict episode (first challenge) during which Gardner asked the students to imagine what the upfront display of the elevators and emerging graphs would involve once each had sent his/her arrangement through the network; it featured the worksheet and real-time display (though this is prior to its display of motion) as mediating artifacts. Also important is the connection made between the shared arrangement of blocks and the predicted emergence of a collection of parallel position time graphs, along with connections between position and time:

Gardner: I'd like to hear from some of you [pause] about what you think we're going to see up front when they send all these up [pointing to the real-time display, inviting visualization].

Student: A bunch of patterns.

Gardner: Esperanza. What do you think their ... Wait, wait, everybody, everybody listen, Nate included. Thank you.

Esperanza: At the point where all of our graphs are going up and down at the same time on the...

Gardner: This little section? [pointing to a worksheet page displaying the required arrangement in the velocity graph]

Esperanza: ... yeah, on that little section all of the ah line graphs will go up the same amount and down the same amount.

Gardner: Um. So what's it gonna look like up there? [pointing to the real-time display] On the graph.

David: Parallel.

Esperanza: They'll be parallel.

Gardner: Oh, uh huh. So they're gonna be parallel and they're gonna do what now?

S: They'll look like ens. 
[Overlapping speech and coughing].

S: They're vees.

S: [girl on camera right side of room]: Are they all gonna do it at the same time?

Gardner: Are they all gonna do it at the same time? They [pointing to camera left side of room] think so. Do you think so?

S: Yes. [from left side].

S: Yes. [from left side].

Gardner: You're not convinced [Pointing to student on right side]. Why do you think they're gonna do it at the same time [looking at left side]?

Esperanza: Cause it all happens at the same time.

S: They're all at the same spot [pointing to the graph on the challenge sheet].

[Overlapping speech similar in content to Esperanza's comment.]

S: Because they're all doing it at the same time.

Gardner: Okay. Okay. She had, we have a couple um, ideas going on there. Yea, they might go anywhere here right [pointing to where the elevators will be displayed]? So you don't know where they're gonna be. They might not even be on our screen. [Laughter from teacher and students.]. Right?

S: Yeah.

Gardner: But, during these three sections, they're saying that no matter where they are, they're gonna be parallel to each other. So they might be like one line's clear up here [pointing to where position graphs will be displayed], one line's clear down here, but these will all be parallel at that moment. That's what they're saying. [pause] So, let's, can anyone tell me why they think it will happen at that moment, and that that will be true?

$\mathrm{S}$ [girl]: Because all of these bars are in the same place on the graph [voice trails off].

Gardner: Okay, and what does this place represent?

S [boy]: Time.

Gardner: Time. And so it's the exact same time for all of you, right?

Esperanza accurately predicted what would occur in the regions where the graphs shared the same arrangements of floors: The graphs will go up and down "the same amount." Another student provided the formal word "parallel," but immediately Esperanza appropriated the use of 
this word and said "they'll be parallel." Up and down the "same amount" was connected with the position-time lines also being parallel, formalizing Esperanza's more conceptual contribution. Gardner then built on one student's attention to time and elicited confirmation about the graphs doing "it at the same time." Some students agreed but she saw some students were "not convinced," leading Esperanza to further extend her initial statement to include temporal ideas. Earlier the reference was to "same amount" and that came to include parallel. Esperanza also saw her initial ideas as including the "same time." It was another student, however, who linked this back to the specific location, "spot," on the graphs. The same spot was seen as pointing to the same time and the implications of this graphical representation of temporal alignment seemed to be understood. Thus, "amounts," "parallel," and the graphical representation of time as a "spot" on a graphical axis with the understanding that this spot denoted the "same" time were all appearing and becoming integrated as part of the classroom discourse.

Gardner drew the class' attention to students' important or generative verbal contributions in a way that made the links between amount, time, and rate salient among the many features of the activity that could be examined ("up and down the same amount" becomes "parallel," x-axis represents time, shared arrangement resulting in parallel position graphs, exploiting a challenge to Esperanza's prediction). Important mathematical practices emerged, focused on connecting claims to and interpreting graphical representations. Gardner's use of the worksheet and visual display together supported a move from conceptual to more formal mathematical discourse, seen in the students' co-constructed prediction ("a bunch of patterns" lead to "they'll go up and down the same amount," which became "parallel"). The worksheet provided a common arrangement as well as invitation to be creative (students could craft any combination of blocks before and after the required segment in seconds 4-6). At an even more general level, the sense of mathematics as the study of pattern (Schoenfeld, 1992) was highlighted for students in a way that made important use of the diversity of their contributions, as their unique individual arrangements provided a diversity of elevator motions and graphical representations of velocity and position of which the class was asked to make mathematical sense.

Interpret Multiple Representations. The next exchange is from the Interpret Multiple Representations episode when the individual elevators' motions were displayed along with the real-time emerging graphs of position and velocity, and features the real-time display (moving elevators, emerging position and velocity graphs) as a mediating artifact. A streaking elevator draws the attention of the class and this expressive artifact invokes a humorous response from both students and Gardner. It also provokes an important discussion of rate. Also important to note is construction of the meaning of intersecting position time graphs:

W: Yes? Okay, go. Yikes.

[Laughter and overlapping speech as class sees elevators appear moving on the screen.]

Gardner: Can you see the segment, um, can you see the four-five-six segment in there?

S [several in unison]: Yeah. 
Gardner: Oh my god. That's too funny. [laughter].

[She is referring to the elevator that streaks up and down.]

Esperanza: I can’t find mine.

R: They're all doing the same thing, did you see that?

Gardner: Yep, it's just like all of a sudden [moves her hands up and down and up to represent the elevators moving together]

Gardner: Even the one at the very, very bottom down there, I think. It's hard to say. I think that's doing the same thing. Yea. It's just not right next to it so, then it goes up a little.

[It takes a little while for all the students to find their elevators].

$\mathrm{R}$ : Jon's is up in the stratosphere somewhere. [Laughter].

Gardner: Yeah, we're assuming it's doing the same thing.

Gardner: So at what speed, Jon? At what speed is that moving?

Jon: I have no idea [laughter].

Gardner: How many floors did it go?

Jon: I didn't, I stopped counting [laughter].

S: It's like eighty miles or something like that a second.

Gardner: Eighty floors a second.

[Laughter. Overlapping speech].

Gardner: What else is happening? [pointing to the graphs]

Jon: No no. Everyone goes crazy again?

Gardner: That's true. Everyone does kind of go crazy again, or do their own thing. What's happening right here? [points to an intersection of two lines on the position-time graph].

Bart: Someone messed up.

Jon: Someone went down.

S: Someone went up and then stopped.

Gardner: But I mean this very point, right there. [pointing to a particular point where two lines intersect] 
Jon: They're crossing?

Gardner: What does it mean?

Jon and Esperanza: They're on the same floor.

Jon: For that second.

S: They're right at theirs.

Gardner: They might be at, what if they're not on a floor?

S: For that second they're on the same ...

S: They're like right next to each other.

Jon: They're passing each other.

Gardner: They're passing each other. So like if you were in an elevator shaft and one's going this way and one's going that way, boom, right there [simulating the movement of the two elevators with arm and hand movement].

The laughter gives a sense of playful engagement. Even though the streaking elevator was off the screen, Gardner raised the sense in which the class was "assuming" it had the same motion as the visible elevators. When asked how fast his elevator was going, Jon focused on the number of floors and said he lost count. Remarkably, the next student then began to articulate a way of talking about rate that spoke to Gardner's question about "speed." Against the backdrop of her significant new qualitative insights, this student began to create a metric for speed: "eighty miles or something like that a second." The units were still uncertain, "miles or something," but the sense is that it was some amount "a second." As is discussed elsewhere, this is not likely to be a full coordination of rate as ratio (when "per" language appears) but it is a significant step in that direction (Stroup, 2002). This is a critical feature of the emergence of a qualitative understanding of rate and amount, as students are able to explore situations where rate varies by developing a significant set of insights about amount, time, comparative rate, and graphical representation before they work on a way of quantifying rate.

As the activity proceeded, colorful language like "crazy" captured the significance of students doing what they wanted on the regions surrounding the required arrangement. Gardner moved to ask about the significance of the intersection of two position-time lines, leading one student to connect the "same floor" with time, noting that they were at that same floor, "for that second." Other students were then able to say what this would be like for the elevators as they move: "right next to each other" or "passing each other." Without the simulation running, they were able to visualize and articulate what this would mean: they are "on the same floor." Throughout, Gardner drew the class' attention to particular student contributions, both verbal and electronic in this case, to direct examination of critical mathematical aspects of the activity. In particular, she helped them connect their predictions to the emergent position graphs, developing a metric for 
speed that links rate and amount, and linking representations (e.g., intersecting position graphs and elevators passing each other).

The mathematical discourse that emerged here engaged students in important roles in interpretation, visualization, and explanation. The real-time display served dual mediating functions in that it provided a visual (material) space containing the class' collectively constructed mathematical objects, while also influencing students' mathematical (ideal) reasoning about relationships among representations and examination of patterns.

The mathematical discourse during these exchanges and across all episodes involved reasoning about change in amount; abstracted time; graphical representations of time, position, and velocity; the significance of parallel and intersecting position-time graphs; coordination of graphs with motion; extending mathematical reasoning beyond what was visible (e.g., the streaking elevator); and the initial emergence of a metric for rate. Their visualization and modeling of elevators' motions also served to link their concrete experience with the abstract mathematical concepts. Shaped by the multiple representations available through the worksheet, calculators, and real-time display, an academic mathematical discourse (Brenner \& Moschkovich, 2002) was developing. In addition, the roles students were playing also involved academic mathematical practices, evidenced by their verbal contributions: Observe/describe (19), Prediction (12), Request clarification (11), Explain (10), Visualization (8), and Evaluation (8) (see Table 2). Gardner contributed more to the verbal interchange than the students over the course of the class ( $60 \%$ for Gardner), but, as explored in more depth later, there was variation in relative contributions across episodes that highlighted the influence of particular mediating artifacts.

Connecting claims to mathematical representations, visualization, and interpreting graphical representations of phenomena was the emerging outcome of the network-mediated activity. Importantly, this discourse formed in a particular learning environment, which strongly influenced the way the network was put to use, and the type of agency with which Gardner and the students could act. As we show next, a variety of artifacts were important mediational means in this environment.

TABLE 2

Nature of Students' Contributions and Their Teacher's Invitations Over the 90-Minute Class Session

\begin{tabular}{ll}
\hline Student's Contributions: & Gardner's Invitations: \\
\hline Observe/describe (19) & Invite prediction (17) \\
Prediction (12) & Invite elaboration (9) \\
Request clarification (11) & Invite explanation (7) \\
Explanation (10) & Invite performance (5) \\
Visualize (8) & Invite clarification (5) \\
Evaluation (8) & Invite test (4) \\
& Invite contribution (3) \\
& Invite play (2) \\
\hline
\end{tabular}

Note. Numbers in parentheses indicate number of instances. 


\section{Mediating Artifacts and Their Influence}

Numerous mediating artifacts were identified including Gardner's verbal invitations, the whiteboard at the front of the room, calculators, worksheets, and the Elevators real-time display. However, in our analyses, the calculators, the real-time display, Gardner's verbal invitations, and the work sheet were central mediating artifacts for the Elevators activity.

Gardner's Verbal Invitations. As seen in the excerpted transcripts, Gardner played a critical role by inviting and capitalizing on substantive student contributions to the discourse. Analysis of classroom talk showed that she coordinated the whole class' activity to keep the group focused on a common task or sequence (e.g., "I want you to do this in an order") and structured the task for students (e.g., "So I want you to try to fill out your position graph"). Coordinating, structuring codes accounted for $24 \%$ of total codes for Elevators. However, her building on and inviting students' contributions (invitations, elaboration, rephrase/restate codes) accounted for $37 \%$ of the total codes for Elevators. This analysis also shows that the Elevators lesson focused largely on inviting contributions to an academic mathematical discourse of predicting, observing, and describing the nature of and relationships among graphical representations, and elaborating on reasoning. Importantly, Gardner's invitations were themselves mediated by the primary artifacts in the lesson, as evidenced by the reduction in her contributions when the focus was on the upfront display.

Figure 5 was developed by counting the number of Gardner's and students' verbal contributions to classroom talk during each episode, to understand how the balance of teacher versus student talk

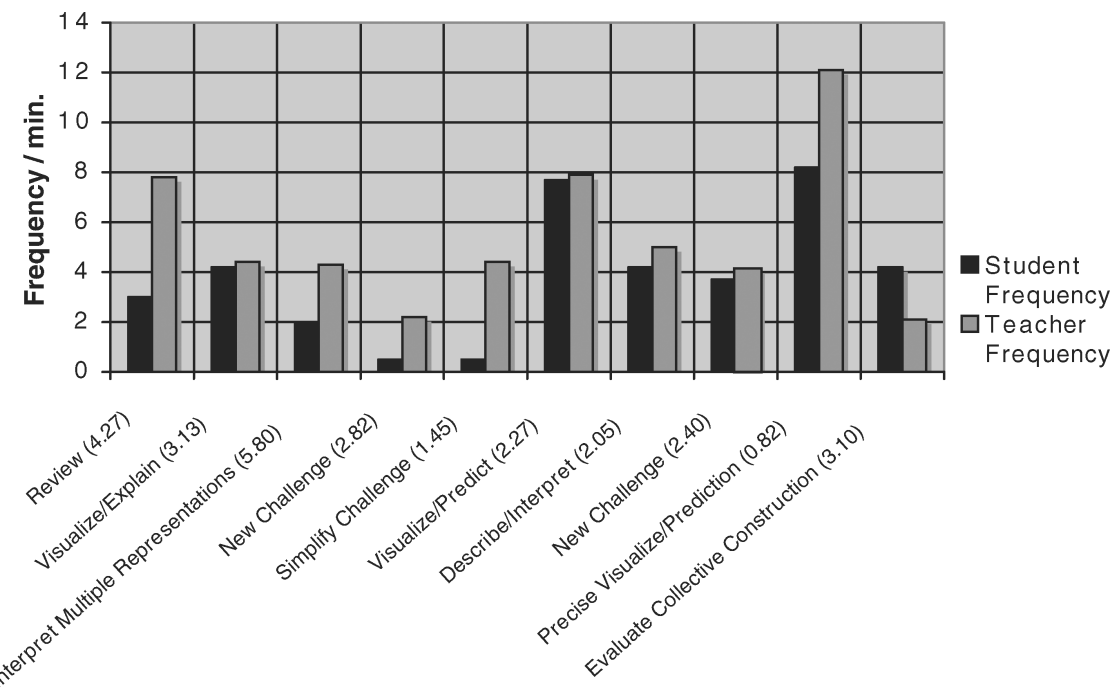

Episodes

FIGURE 5 Student and teacher verbal contributions.

Note. The numbers in parentheses represent minutes (e.g., $4.27=4$ minutes, 16 seconds). 
varied over the course of the class. Our analysis indicated that particular of Gardner's questions or directions signaled the beginning of new episodes (directing the class' attention to particular relationships, representations; inviting prediction, explanation). During the Visualize/Explain, Visualize/Predict, and Describe/Interpret episodes, the balance between students' and Gardner's contributions was roughly equal $(52 \%, 51 \%$, and $55 \%$, respectively). These episodes all had the upfront, real-time display as the focus of discussion. Gardner dominated episodes in the Elevators lesson when she posed a new challenge and then needed to clarify it for students (New Challenge, Simplify Challenge episodes). Students were given more space to contribute when they were asked to predict what would emerge in the upfront real-time display, and when they analyzed and described the multiple, linked representations (e.g., motion of elevators, emerging position and velocity graphs; Visualize/Explain, Visualize/Predict, Describe/Interpret, Precise Visualize/Prediction episodes). Finally, students dominated when they evaluated how well they had done as a collective in accomplishing the final challenge of the session. That the proportion of teacher/student talk was more balanced when the upfront display was the focus points to the important mediating function it played, which we explore later.

First though, simply counting invitations does not fully capture the mediating function of Gardner's invitations, because some were particularly important in shaping the discussion or exploration. For example, in setting expectations for students' arrangements of elevator floors for the second simulation, her invitation was to, "Try and do something interesting on either side. ... If you want it to be it can be terribly interesting." In this fashion, Gardner encouraged students to contribute unique or provocative arrangements, as in the streaking elevator, that could provide important fodder for discussion and exploration of mathematical structures. As a mediating means, then, her influence in Elevators was one of opening a wide space of possibility for contributions to academic mathematical discourse and practice.

Worksheets and Calculators as Private Spaces. In the Elevators PartSim, the worksheet tasks provided a common arrangement of elevator floors, and partially determined the sequence of tasks to be undertaken in preparation for running the simulation. They also provided private and small group space for students, as well as space for investigating relationships between elevator motion and graphs, and for predicting relationships. However, with challenges such as "do whatever you want on either side," of a required arrangement, and "use as many blocks as you want to have your elevator end on the -2 floor," the worksheet tasks provided an invitation to be creative or unique. For example, the challenge with the required arrangement in seconds 4-6 that was the focus of the earlier excerpt directed students to, "Make a complicated graph for your elevator and have it use five blocks as shown below (it should also have blocks on either side of these five)." As a result, the PartSims challenges were highly generative in that students were asked to create configurations to complete a task (e.g., make an elevator end on a given floor or pass a certain floor at a specific time), but given the space to complete the challenge in diverse ways. The Part Sims worksheet mediated divergent ways for students to solve a problem mathematically, resulting in various objects, all of which were "right" answers.

Calculators also served as important artifacts in the session. Students' use of them created a dynamic private space for testing arrangements and examining relationships among varying configurations of floors and elevator velocity. They allowed students to immediately self-assess their arrangements, make necessary or desired changes, and explore the relationships among representations of rate and amount. 
Together, Gardner's invitations, the generative nature of the problems posed in the worksheet, and the private space of the calculator providing a safe space for students to try out their thinking created an important context for exercising agency in producing multiple solutions. Shown next, as the activity moved to focus on the real-time upfront display, the technology then allowed the students to visualize and analyze, as well as reason with, the emergent objects that resulted from these exercises of agency. The following analysis highlights the profound influence that the dynamic display had on the emerging discourse and practice.

The Real-Time Display as a Public Space. The real-time display in the Elevators lesson provided a common visual space that focused the class' attention. There are, of course, other public displays in classrooms that serve this same purpose (i.e., white boards, overheads, chalk boards). However, the nature of this visual space was markedly different given the real-time development of the system being displayed, the multiple, linked representations of the relationships among variables, and that the representations were the result of individual contributions that together produced a complex system. This display showed the emergent system as it evolved; contained representations of both individual and collective activity (individual elevators' motion; emerging graphs of class' inputs); and provided multiple notational systems of elements of the phenomenon (position graph; velocity graph; motion of elevators). Returning to the earlier excerpt during which students and Gardner constructed a shared understanding of the meaning of the graphs in relation to the motion of the elevators, the public space and Gardner's questions prompted students to make their thinking visible. They shared in the reasoning about the meaning of intersecting position graphs as representing two elevators passing the same floor at the same time, building on each others' ideas and Gardner's prompting questions. Students' varied and individual contributions were brought together in this public space to produce a set of representations that they used as tools for thinking and talking through relationships and communicating mathematically.

Thus, the dynamic, real-time display in the PartSim, created through the collective contributions of the group, mediated the development of mathematical discursive practices in particular ways. The dynamic notational system in the PartSim activity represented the group's multiple pathways to multiple endpoints (see Stroup, Ares, \& Hurford, 2004; Stroup, Ares, Hurford, \& Lesh, 2007), where varied contributions constituted the emergent structures that no one could pre-determine, and all of which were "correct."

\section{Emergent Objects and Outcomes}

The resulting objects of discussion and analysis in Elevators were students' individual constructions of elevators' motion, and the emergent system and graphs that formed as a result of individuals' collective contributions. An example is the streaking elevator that, when analyzed, fostered the class' construction of an initial term for rate. The source of the insight was a studentconstructed object that had generative possibilities because there was no pre-determined concept of interest. Further, student understanding emerged from having been a legitimate participant in the construction of mathematical discourse and practice. Students used and produced mathematics through their appropriation of authentic modes of participation. Their knowledge and 
insight emerged from active inquiry using the practices and tools of mathematics, scaffolding their meaningful engagement with the insights and formalism of mathematics.

\section{DISCUSSION}

Our goal was to examine new, networked technologies as important artifact that structures activity. We explored the mediating function of the networked technology, particularly the classroom mathematical practices that emerged. Aspects of the network (e.g., real-time display of emergent system, dynamic space of calculators) emerged as important mediators of students' and Gardner's roles, and the development of group-level mathematical discourse. The following discussion centers on participants' roles and the mediating roles of artifacts in groups' production of mathematical discourse and practice.

\section{Production of Group-Level Mathematical Discourse}

PartSims are designed in part to leverage group construction of learning, knowledge, and skills. Individuals co-create mathematical objects that the group then analyzes collectively, building a community-level set of generative mathematical understandings and ways of speaking. Paraphrasing Moschkovich (2002), being an agent in the co-construction of a complex, dynamic system, publicly displayed and analyzed, can provide a venue for using mathematical language, tools, and representations, and can serve as a reason for developing more formal mathematical activity (p. 9). The role of the primary mediating artifacts is one of shifting from learning existing content to producing content. Our analyses show that the mediating function of the technology served to shape students' contributions and Gardner's invitations in ways that highlight the generative nature of the practices involved.

\section{Dynamic Artifacts and Interactive Media}

The calculator and the upfront space were identified as important features of PartSims as mediating artifacts. Kaput's (1998) work on inert versus dynamic artifacts and students' acting on representations is helpful here to pinpoint unique affordances of the calculator space. Traditionally in many math classrooms, the static notational system embodied in calculators is used to act on the textbook- or teacher-provided representations "to reason about and make sense of [the] situation" (Kaput, 1998, p. 258). The argument is that this action on static notation sets up a one-way relationship between mathematics and experience, denying students any control of either. In the PartSim lesson, the dynamic notational system embodied in the calculators involved varying representations of velocity and position, and allowed students to act on:

... such motion phenomena [e.g., velocities, positions, times and combinations of these in graphs] ... [that] are not only modeled by the notations that describe them, they can be controlled by those notations [in this case, by the velocity graphs students created]... These kinds of affordances turn 
a fundamental representational relationship between mathematics and experience from one-way to

bi-directions. (Kaput, 1998, pp. 258, 259)

Once the upfront display was the focus, the interactivity of the Elevators PartSim was highlighted in another way. Again, Kaput's (1998) work is helpful here to draw attention to the upfront display as a "dynamic interactive medium" (p. 262) (e.g., real-time emerging graphical representations, moving elevators) that allowed the class to animate and link notation systems. Together, these features of the system were important supports for the development of mathematical understandings and discourse.

\section{Authentic Mathematical Discourses}

A wide variety of discursive mathematical practices was fostered using the Elevator activity, as evidenced by the group-level development of ways of speaking and the roles played by participants. The group developed ways of communicating mathematically, of using culturally valued mathematical artifacts (e.g., symbols, notation systems), and ways of interacting that "signal (that one is playing) a socially meaningful role" (Gee, 1999, p. 131, cited in Moschkovich, 2002, p. 198) in mathematical activity. Interactivity with the public space resulted in student roles that can be characterized as "playing along" versus "playing a part:"

\footnotetext{
Playing along invokes a sense of constraint and limited possibility.... Playing a part, on the other hand, involves one's own explorations being juxtaposed to others', to the group's evolving notion of the domain, and to the more formalized insights of the dynamic communities of science and mathematics. (Stroup, Ares, \& Hurford, 2005, p. 192)
}

These ways of participating have important implications for movement toward activity that is central to communities of mathematicians (Lave \& Wenger, 1991). For example, the Elevator participatory simulation engendered powerful forms of calculus-related reasoning (Stroup, 2002), as when the class explored rates of change in a qualitative way in response to the streaking elevator using a student's initial metric ("eighty miles or something like that a second") and Gardner's clarification ("eighty floors a second"). Relationships among rates and amounts were linked through the class' use of multiple representations in examining and explaining patterns. Students' graphs and insights worked together in a public and social way, and supported learning as evolving forms of participation in academic mathematics. The combined emphasis on a variety of notational systems - real-time graphical representations of dynamic phenomena, and visual inscriptions of elevators-supported students' generative appropriation of the discourses and practices of academic mathematics.

\section{ACKNOWLEDGMENT}

Critical to the development of this line of research was funding from the National Science Foundation: Grant \# 09093 entitled CAREER: Learning Entropy and Energy Project and grant \# 126227 entitled Integrated Simulation and Modeling Environment, as well as support from 
Texas Instruments. Any opinions, finding, and conclusions or recommendation expressed in this material are those of the authors and do not necessarily reflect the views of the National Science Foundation or Texas Instruments.

\section{REFERENCES}

Brenner, M. E., \& Moschkovich, J. (Eds.). (2002). Everyday and academic mathematics in the classroom. Journal for Research in Mathematics Education Monograph Series, Number 11.

Cobb, P. (2002). Reasoning with tools and inscriptions. Journal of the Learning Sciences, 11(2-3), 187-215.

Cole, M. (1996). Cultural psychology: A once and future discipline. Cambridge, MA: Harvard University Press.

Cole, M., \& Engeström, Y. (1993). A cultural-historical approach to distributed cognition. In G. Salomon (Ed.), Distributed cognitions: Psychological and educational considerations (pp. 1-46). New York: Cambridge University Press.

Damazio, A. (2001). Mathematical cognition in the classroom: A cultural-historical approach. In M. Hedegaard (Ed.), Learning in classrooms: A cultural-historical approach (pp. 191-210). Oxford: Aarhus University Press.

Dede, C. (2000). Emerging influences of information technology on school curriculum. Journal of Curriculum Studies, 32(2), 281-303.

Fendel, D., Resek, D., Alper, L., \& Fraser, S. (1997). The interactive mathematics program Year 1. Berkeley, CA: Key Curriculum Press.

Gee, J. P. (1999). An introduction to discourse analysis: Theory and method. New York: Routledge.

Geertz, C. (1973). Think description: Toward an interpretive theory of culture. In C. Geertz (Ed.), The interpretation of cultures: Selected essays (pp. 3-30). New York: Basic Books.

Hershkowitz, R., \& Schwarz, B. (1999). Reflective processes in a mathematics classroom with a rich learning environment. Cognition and Instruction, 17(1), 65-91.

Hung, D. W. L. (2001). Conjectured ideas as mediating artifacts for the appropriation of mathematical ideas. Journal of Mathematical Behavior, 20, 247-262.

Hung, D. W. L. (2002). Metaphorical ideas as mediating artifacts for the social construction of knowledge: Implications from the writings of Dewey and Vygotsky. International Journal of Instructional Media, 29(2), 197-214.

Kaput, J. J. (1992). Technology and mathematics education. In D. A. Grouws (Ed.), Handbook of research on mathematics teaching and learning (pp. 515-556). Reston, VA: National Council of Teachers of Mathematics.

Kaput, J. J. (1994). Access to calculus: New routes to old roots. In A. Schoenfeld (Ed.), Mathematical thinking and problem solving (pp. 77-166). Hillsdale, NJ: Lawrence Erlbaum.

Kaput, J. J. (1998). Representations, inscriptions, descriptions, and learning: A kaleidoscope of windows. Journal of Mathematical Behavior, 17(2), 256-281.

Kaput, J. J., \& Hegedus, S. (2002). Exploiting classroom connectivity by aggregating student constructions to create new learning opportunities. Paper presented at the 26th Conference of the International Group for the Psychology of Mathematics Education, Norwich, UK.

Lave, J., \& Wenger, E. (1991). Situated learning: Legitimate peripheral participation. New York: Cambridge University Press.

McClain, K., \& Cobb, P. (2001). Supporting students' ability to reason about data. Educational Studies in Mathematics, 45(1-3), 103-129.

Miles, M. B., \& Huberman, A. M. (1994). Qualitative data analysis. Thousand Oaks, CA: Sage.

Moschkovich, J. (2002). A situated and sociocultural perspective on bilingual mathematics learners. Mathematical Thinking and Learning, 4(2\&3), 189-212.

National Council of Teachers of Mathematics (2006). Principles and standards for school mathematics. Retrieved November 18, 2006, from http://my.nctm.org/standards/document.htm.

Noble, T., Nemirovsky, R., Wright, T., \& Tierney, C. (2001). Experiencing change: The mathematics of change in multiple environments. Journal for Research in Mathematics Education, 32(2), 85-108.

Roschelle, J., Kaput, J. J., \& Stroup, W. M. (2000). SimCalc: Accelerating students' engagement with the mathematics of change. In M. J. Jacobson (Ed.), Innovations in science and mathematics (pp. 47-76). Hilllsdale, NJ: Erlbaum.

Roschelle, J., \& Pea, R. (1999). Trajectories from today's WWW to a powerful educational infrastructure. Educational Researcher, 8(5), 22-25. 
Saxe, G. (2002). Children's developing mathematics in collective practices: A framework for analysis. Journal of the Learning Sciences, 11(2-3), 275-300.

Schwarz, B. B., \& Hershkowitz, R. (2001). Production and transformation of computer artifacts toward construction of meaning in mathematics. Mind, Culture, and Activity, 8(3), 250-267.

Schoenfeld, A. H. (1992). Learning to think mathematically: Problem solving, metacognition, and sense making in mathematics. In D. A. Grouws (Ed.), Handbook of research on mathematics teaching and learning (pp. 334-370). New York: Macmillan.

Smagorinsky, P. (1995). The social construction of data: Methodological problems of investigating learning in the zone of proximal development. [Electronic version.] Review of Educational Research, 65(3), 191-212.

Strauss, A. L., \& Corbin, J. (1990). Basics of qualitative research: Grounded theory procedures and techniques. Newbury Park: CA: Sage.

Stroup, W. M. (2002). Understanding qualitative calculus: A structural synthesis of learning research. International Journal of Computers for Mathematical Learning, 7, 167-215.

Stroup, W. M., Ares, N., \& Hurford, A. (2004). A taxonomy of generative activity design supported by next-generation classroom networks. In D. McDougal, \& J. Ross (Eds.), Proceedings of the twenty-sixth annual meeting of the Psychology of Mathematics Education (pp. 1401-1410). Toronto, OISE/UT.

Stroup, W. M., Ares, N., \& Hurford, A. (2005). A dialectic analysis of generativity: Issues of network-supported design in mathematics and science. Mathematical Thinking and Learning, 7(3), 181-206.

Stroup, W. M., Ares, N., \& Lesh, R. A. (2007). Diversity by design: The what, why and how of generativity in nextgeneration classroom networks. In R. A. Lesh, \& J. J. Kaput (Eds.), Foundations of the Future: Twenty-first century models and modeling (pp. 367-394). Hillsdale, NJ: Lawrence Erlbaum.

Vygotsky, L. S. (1987). Thinking and speech. In R. W. Reiber, \& A. S. Carton (Eds.), The collected works of L. S. Vygotsky, vol. 1 (pp. 39-285). New York: Plenum.

Wells, G. (2002). Dialogue and activity theory. Mind, Culture, and Activity, 9(1), 43-66.

Wertsch, J. V. (1995). The need for action in sociocultural research. In J. V. Wertsch, P. d. Rio, \& A. Alvarez (Eds.), Sociocultural studies of minds (pp. 56-74). New York: Cambridge University Press.

Wilensky, U., \& Stroup, W. (1999). Participatory simulations: Network-based design for systems learning in classrooms. Proceedings of the Conference on Computer-Supported Collaborative Learning, CSCL '99, Stanford University.

Wilensky, U., \& Stroup, W. (2000). Networked gridlock: Students enacting complex dynamical phenomena with the HubNet architecture. In B. Fishman, \& S. O'Connor-Divelbiss (Eds.), Proceedings of the Fourth International Conference of the Learning Sciences (pp. 282-289). Mahwah, NJ: Lawrence Erlbaum. 
APPENDIX

Coding Scheme

\begin{tabular}{|c|c|}
\hline Students' Contributions & Gardner's Contributions \\
\hline Everyday mathematics: & Everyday mathematics: \\
\hline Comparison to specific real-world setting & $\begin{array}{l}\text { Comparison to specific real-world } \\
\text { setting }\end{array}$ \\
\hline Rephrase into everyday terminology & $\begin{array}{l}\text { Rephrase into everyday } \\
\text { terminology }\end{array}$ \\
\hline Reference to personal knowledge & Reference to personal knowledge \\
\hline Situation-specific units of analysis & Situation-specific units of analysis \\
\hline Use of informal methods & Use of informal methods \\
\hline Academic mathematics: & Academic mathematics: \\
\hline Conjecture & Invite explanation \\
\hline Test & Invite confirmation \\
\hline Hypothesize & Invite clarification \\
\hline Abstracting & Invite prediction \\
\hline Generalize & Invite evaluation \\
\hline Explain & Invite elaboration \\
\hline Synthesize & Invite comparison \\
\hline Visualize & Elaborate on student contribution \\
\hline Predict & Evaluation \\
\hline Compare/contrast & Explanation \\
\hline Observe/describe & Summarize \\
\hline Add precision & Generalize \\
\hline Elaborate (on own answer or on another's contribution) & Symbolize \\
\hline Symbolize & Add precision \\
\hline Emergent codes: & Observe/describe \\
\hline Perform procedure & Rephrase into formal language \\
\hline \multicolumn{2}{|l|}{ Evaluate } \\
\hline Pose question & Emergent codes: \\
\hline Request clarification & $\begin{array}{l}\text { Structure task [setting up the task } \\
\text { ("we're going to put these blocks } \\
\text { in and see what they make the } \\
\text { elevator do")] }\end{array}$ \\
\hline Play & $\begin{array}{l}\text { Coordinate whole class (getting or } \\
\text { keeping all students doing the } \\
\text { same thing) }\end{array}$ \\
\hline Report result & Pose known-answer question \\
\hline Request evaluation & Invite performance of procedure \\
\hline \multirow[t]{5}{*}{ Fill in the blank } & $\begin{array}{l}\text { Rephrase or restate student } \\
\text { explanation }\end{array}$ \\
\hline & Model procedure \\
\hline & Invite contribution \\
\hline & Invite play \\
\hline & Request information \\
\hline
\end{tabular}

